\title{
Non pharmacological nursing care addressing urinary disorders following acquired brain injury during in hospital rehabilitation - A scoping review
}

\author{
Lisbet Fog, Mette Nørtoft Nielsen and Lena Aadal* \\ Department of Clinical Medicine Aarhus University, Denmark
}

\begin{abstract}
Approximately 10 million first-ever strokes and 27 million new cases of traumatic brain injury occur in the world annually. Urinary disorders are frequent after an acquired moderate to severe brain injury and rehabilitation requires multidisciplinary contributions where each member has a strong professional identity. Nurses are a significant member of the rehabilitation team, but their contributions has been found vague and unclear.

This scoping review in six steps focuses on the nurses' contribution in addressing urinary disorders during hospital based rehabilitation. 178 studies were identified in five databases using the PICO tool, Bolerian terms and MESH words and 19 were included

Rehabilitation of urinary disorders is complex and require interdisciplinary efforts. Descriptions of nurses mono-professional contributions are scarce especially among teaching, facilitation of skills and psychological care. Supervision from specialist nurses, systematic assessment and examination of the patient's urinary symptoms is a prerequisite continence-promoting interventions. Nurses contributions vary between specific types of urinary disorders but patients with physical disturbances may need compensatory treatment, aids, physical support and adapted intake while patients with cognitive consequences of ABI may need an organized rehabilitating environment of reminding, visualizing or regular assistance to use the toilet to facilitate continence.
\end{abstract}

\section{Background}

The population in this review is adult patients with urinary disorders following an acquired moderate to severe brain injury (ABI) during hospital-based neurorehabilitation. Functional changes in relation to excretion of urine are described as a complex rehabilitation task which requires competences from a well-educated and closely cooperating multidisciplinary team. Interdisciplinary teamwork requires that each member has a strong professional identity and understanding of their individual responsibility. Nurses have traditionally been a significant member of the rehabilitation team in rehabilitation after ABI but their contributions has been found vague and unclear by nurses, patients and collaborators. This scoping review focuses on the nursing contribution in addressing urinary disorders after ABI.

The etiology of the injury may be stroke, subarachnoid hematoma, trauma or anoxia after e.g. cardiac arrest characterized by individual sequelae of sensory motor and mental impairments including cognitive and behavioral disorders, emotional changes, and various levels of consciousness. Approximately 10 million first-ever strokes and 27 million new cases of TBI occur in the world annually [1,2]. Patients with moderate to severe $\mathrm{ABI}$ often experience urinary incontinence and other urinary disorders especially during the period of intensive and hospital- based neurorehabilitation [3-7]. Sensory motor as well as cognitive disturbances may challenge the ability to sense and recognize the urge to urinate and expose it if it is inconvenient. The patient should be able to take initiative and act, be able to move, locate the toilet, recognize the toilet, handle the clothes, sit down and able to let the urine pass [8]. Nurses are with the patient 24/7 and are therefore the focal point to perform rehabilitation activities beyond treatment and facilitate skills practice in assuming that they recognize the effort as legitimate nursing activities and possess the needed knowledge and experience [9].

The reported prevalence of urinary disorders varies, but appears to occur in between 40 and $80 \%$ in the days and weeks after the onset of the moderate to severe injury [10]. Among patients with stroke 25\% experience the problem persists at discharge and $15 \%$ after one year [10]. Similar frequency has been found in patients with traumatic brain injury, where $62 \%$ were incontinent at admission to a rehabilitation hospital, $37 \%$ at discharge and $18 \%$ continued problems at 6 months. Residual urine was prevalent in $8 \% 6$ weeks after the onset [11].

The socio- economic consequences of urinary disturbances are well known $[3,12]$. Studies claim that urinary disturbances causes increased dependency in daily life, reduced participation in social contexts and reduced quality of life [13]. In a long-term perspective, urinary disorders may lead to isolation and negatively affect mental health, the patient's self-perception and self-esteem [13]. Further more urinary incontinence, urinary retention or incomplete bladder emptying increases the risk of urinary tract infection [14], and poses a significant health risk as it is associated with increased morbidity and death [15].

${ }^{*}$ Correspondence to: Lena Aadal, Associate Professor, Department of Clinical Medicine Aarhus University, Head of Clinical Nursing research Hammel neurorehabilitation and University Research Clinic Voldbyvej 158450 Hammel, Denmark, Tel: 4578419055/4521833364,E-mail: lena.aadal@midt.rm.dk

Received: April 16, 2018; Accepted: May 14, 2019; Published: May 20, 2019 
Recent research suggests that the frequent complication of urinary tract infections might be influenced by a disrupted interaction between the central nervous system and the immune system contributes to the development of infection in patients with acquired brain injury [16]. Infections with fever and repeated fever episodes cause increased energy and protein expenditure which may extend the rehabilitation process and influence the rehabilitation outcome negatively [17].

Summing up urinary disturbances are very well-known following a moderate to severe acquired brain injury and the function may be temporarily or permanently affected depending on the underlying causal relationships. The interdisciplinary evidence of interventions addressing urinary disorders is scarce [10]. Surprisingly only a few nursing interventions that not only diagnose but also address nursing initiatives in a rehabilitative perspective has been described despite a national Board of health requirement of data collection and intervention in relation to the patient's potential or current urination problems $[18,19]$. Traditionally, the care for the patients' physical needs has been a core element in nursing practice. Moreover, nurses are key persons in the prevention of complications [20].

Taken the intrusive personal and economic consequences into consideration, it is urgent that nurses assess and initiates both researchbased interventions and experience-based practices in order to meet the complex needs of patients with urinary disorders during rehabilitation after acquired brain injury. Hence this scoping review focuses on nursing-related initiatives in order to identify mono- professional contributions in the rehabilitation of people with urinary disorders after acquired brain injury.

\section{Aim}

This scoping review describes non-pharmacological nursing contributions addressing urinary disorders in patients with moderate to severe brain injuries admitted to hospital based rehabilitation.

\section{Method}

Rehabilitation addressing urinary disorders is scarcely described and the quality of the studies is fluctuating [10]. Hence the six-step systematic approach of scoping review is used to identify the current evidence [21]. First and last author identified the study questions, and prepared the literature search strategy using the patient, intervention, comparison, outcome (PICO) as a strategy tool in collaboration with research librarian, who conducted the searches in the PubMed, Cinahl, Web of Science, Joanna Briggs Institute, Embase and Psych info databases supplemented by hand search from the reference lists in February 2019. All authors collaborated on identifying relevant studies based on title and abstract. Included studies were distributed among the authors for data extraction, and uncertainty was discussed until consensus. Thematic analysis (charting the data), summarizing and reporting results was conducted by the authors in a process where experts from clinical practice were consulted for recognition of patterns.

\section{Search strategy}

The search strategy was developed in collaboration with a research librarian (Table 1). The scarcity of studies conducted in the ABI population required a broad search.

The search in five databases supplemented by hand search resulted in 178 hits which were in and excluded (Figure 1) using the following criteria's:
Table 1. Literature search strategy using the patient, intervention, comparison, outcome (PICO) as a strategy tool, MESH words marked by * and Boleric terms to combine the four facets

\begin{tabular}{|l|l|l|l|c|}
\hline OR & \multicolumn{1}{|c|}{ Facet 1 } & \multicolumn{1}{|c|}{ Facet 2 } & Facet 3 & Facet 4 \\
\hline & $\begin{array}{l}\text { AND } \\
\text { Urinary incontinence* } \\
\text { Urinary disturbance* } \\
\text { Urination disorder* } \\
\text { Bladder incontinence } \\
\text { Bladder management } \\
\begin{array}{l}\text { Bladder continence } \\
\text { Urinary tract dys function } \\
\text { Bladder rehabilitation } \\
\text { Bladder retraining } \\
\text { Bladder function Bladder } \\
\text { dysfunction Urodynamic* }\end{array}\end{array}$ & $\begin{array}{l}\text { AND } \\
\text { Brain injur* Head } \\
\text { trauma Brain } \\
\text { damage Brain } \\
\text { lesion Traumatic } \\
\text { head Traumatic } \\
\text { brain Brain } \\
\text { trauma }\end{array}$ & $\begin{array}{l}\text { Nehabilitation } \\
\text { Neurorehabilitation }\end{array}$ & Outpatient* \\
\hline
\end{tabular}

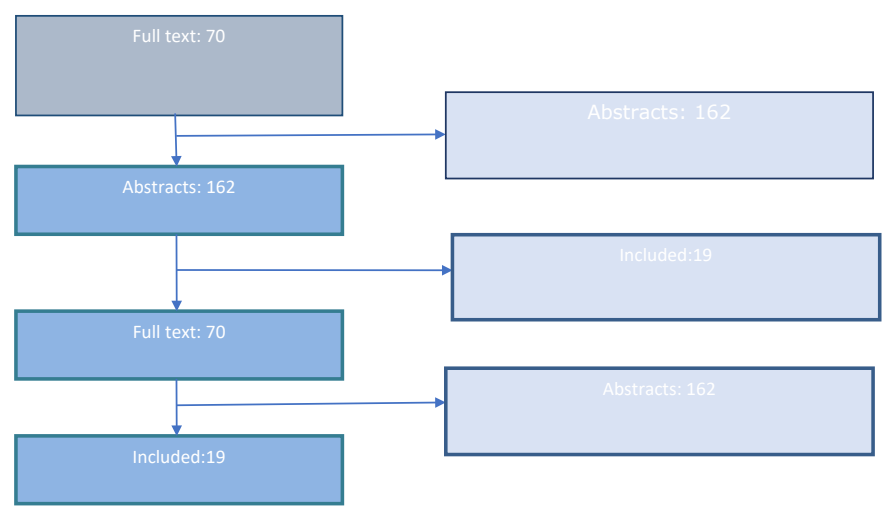

Figure 1. Flowchart in- and exclusion

Inclusion:

- Adults $>18$ years with acquired brain injury

- In hospital rehabilitation

- Studies regardless of design

- Peer reviewed

- Published in english, german or nordic language

- Describes non pharmacologic nursing care

- Published in or later than 2004

\section{Exclusion:}

- Pharmacological nursing interventions

- Published before 2004 (Figure 1 about here)

\section{Results}

Functional changes in relation to excretion of urine are described as a complex rehabilitation task, which can not only be addressed by nurses. Assessment, initiatives and compensatory strategies must be developed and implemented by a well-educated and closely cooperating multidisciplinary team [8,22-25]. Nurses contributions are integrated in this work and systematic assessment of urinary challenges and use of clinical guidelines are described as fundamental in relation to the development of care interventions despite the knowledge base for this assumption is described as being rather scarce $[10,16,22,23,25,26]$. The extracted nursing-related contributions with a rehabilitating focal point will be described in the following. 


\section{Nursing assessments, interventions and compensatory strategies in relation to patients with urinary disorders}

Assessment and rehabilitation in relation to excretion of urine are described as a complex rehabilitation task, and following this a need for educating and developing specialists / spearheads is emphasized in order to solve the nurses professional responsibility in the team collaboration $[10,22,27$,$] . Education as continence nurses$ are needed with specific focus on incontinence types, treatment options, brain injury relationship, and urinary incontinence treatment as these aspects appears to have a nursing pivot [23,22,2527]. Further more are organizational initiatives required to ensure the access to structured support from both teams and specialists, in order to carry out a structured assessment and concrete nursing initiatives $[3,22]$.

\section{Systematic assessment and examination}

Systematic assessment and examination of the patient's urinary symptoms is a prerequisite for the selection of continence-promoting measures and remedial or relieving interventions addressing the patient's urinary symptoms $[3,8,12,22,26-28]$. In particular it is important that the healthcare professionals ask the patient about continence [26,29]. In addition, the systematic nursing investigations include the following:

Bladder anamnesis- urination pattern before the brain injury [11].

Assessment of past and present diseases focusing on the etiology of the micturition disorder [13,30,38].

Assessment of residual urine [3,12,22,27].

Assessment of actual urination pattern [12,22,26,30]

Review of patient's medical treatment [22]

Assessment of nutritional status [22]

Assessment of physical mobility [22,27]

Assessment of cognitive status [22]

Communicative ability [22] [22]

Patient's belief, goals, and cultural attitude to continence treatment

\section{Control for urinary tract infection [22]}

Assessment for constipation [22]

The aggregate of nursing information complements the team in identifying the etiology and possible rehabilitation strategies - the type of incontinence (note 1), which affects the bladder function, the patient's cognitive function and the patient's self-perception of the problem. The following describe the nurses' contributions in addressing the specific types of incontinence and urinary disorders.

\section{Use of long term catheter}

The prescription of catheter therapy is a medical task but takes place in close dialogue with the nurse, who performs the interventions related to the treatment. It is generally recommended to avoid or restrain use of long term catheters, in order to reduce the risk of urinary tract infection $[3,8,12,23,26-28]$. When the patient has a longterm need a suprapubic catheter should be used to replace long term urethral catheters ${ }^{1}$.

\section{Functional incontinence}

Functional incontinence is associated with normal bladder function and disturbed voiding due to physical or cognitive impairments preventing. An inability of a usually continent person to reach the toilet in time to avoid the unintentional loss of urine [28]. Patients with physical or cognitive problems may need an organized rehabilitating environment of reminding, visualizing or regular assistance to use the toilet to facilitate continence:

Help the patients to regain mobility as soon as possible $[7,30]$.

Visual aids, such as colorful and clear wall signs for the toilet [31].

Communication cards may help patients who have difficulty in expressing their needs. Similarly, such cards can be used by staff to enquire about toileting needs if the patient has severely impaired understanding of spoken or written words [12].

Using short sentences and stressing key words in a quiet environment may be sufficient to ensure understanding and successful communication [31].

A hand bell can be useful if patients have difficulty in using the bell-systems [31].

The ability to remove clothing, cleanse and re-dress may be affected. Use of clothing that can be removed easily, and that is carefully chosen to suit the functional ability and lifestyle of individual patients, may be beneficial, for example using adapted clothing with Velcro fasteners [31].

Patients with functional incontinence may benefit from short-term use of containment products, such as pads or urinary sheaths [12].

\section{Urge incontinence}

Is the complaint of involuntary leakage accompanied by or immediately preceded by urgency. It is often associated with detrusor over activity, but can be due to other forms of urethra-vesical dysfunction $[28,32]$. In order to establish a fluid-loading and bladder emptying routine every three to four hours without urgency or incontinence, the nurse should encourage the patient to extend the time between each void by deferring use of the toilet on the initial sensation of urge [12]. Bladders retraining with urge suppression involves three components: educating patients about the mechanisms underlying incontinence and continence, a scheduled voiding regimen with gradually progressive voiding intervals and an urgency control strategy using distraction and relaxation techniques $[5,31,33]$.

Pelvic Muscle rehabilitation is suggested as a good method to treat urinary incontinence. Pelvic floor exercises consist of a program of repeated voluntary pelvic floor muscle contractions taught by a health care professional $[4,5,27,29,33$,]. Further recommendations are -

Establish bath rom training with easy access to a bedpan or toilet and recommend of wearing clothing that can be easily adjusted for voiding $[27,31]$.

Encourage bladder emptying before physical activities [31]

\section{Stress incontinence}

Is the complaint of involuntary leakage on effort or exertion, sneezing or coughing [32.]. It is usually caused by pelvic floor weakness or damage, sphincter incompetence [28]. Lifestyle interventions are often the first method of control. These interventions include: 
Weight loss, smoking cessation, dietary changes, managing fluid intake and bowel management [12].

Avoid bladder irritants such as carbonated and caffeinated beverages, citrus juices and aspartame (two or fewer servings a day of caffeinated beverages). Water is not irritant or diuretic [33].

Encourage bladder emptying before physical activities [31]. [7]

Pelvic floor exercises can improve bladder management in women

Support a daily fluid intake of two-three liters to prevent exacerbation of the incontinence due to concentrated urine or urinary tract infection $[8,29,30,33]$.

\section{Urinary retention leading to incontinence}

Acute retention of urine is defined as a painful, palpable or percussable bladder, when the patient is unable to pass any urine. Although acute retention is usually thought of as a painful, in certain circumstances (for instance in some cases of stroke) pain may not be a presenting feature. It may be associated with detrusor over- or underactivity [28]. Chronic urinary retention or voiding symptoms associated with obstruction or underactive detrusor is characterized by a non- painful bladder, which remains palpable or percussable after the patient has passed urine.

These patients may be incontinent [28]. The contributions from nurses are:

Katerisation [22,31] The bladder should be drained using either an intermittent catheter (preferable method) or a short-term indwelling catheter with a valve attached to allow timed bladder emptying $[12,33$,$] .$

Minimum possible catheter size is used to avoid discomfort and risk of lesion [22].

Perform a post void residual (PVR) ultrasound; if results show a high PVR level, perform periodic catheterization [33].

Guidelines suggest $100-150 \mathrm{ml}$ of residual urine should be considered problematic. If a patient has bothersome residual urinary volume of $60-150 \mathrm{ml}$, bladder emptying should be attempted and then re-attempted. Where residual urinary volumes persist, intermittent catheterization may be necessary [12]

Initiation of timed voiding with fixed time intervals [12].

Prompted voiding using verbal toileting reminders and positive feed back planned from based on systematic registration of urinations $[3,5,12,22,26,27,33$, $]$.

Assisting men to pass urine in standing position helps to prevent incomplete bladder emptying and reduces infection risks [30].

Double voiding technique recommending time, positioning and attempt to pee twice can enable effective bladder emptying. Encourage patients to sit comfortably on the toilet. Leaning forwards with legs slightly apart allows the pelvic floor muscles to relax and achieve a successful urinary void [12].

Encouraging a diet rich in fibre and a fluid intake of at least 1.5 litres every day to prevent constipation $[33,12,30]$.

\section{Nocturia}

Is any involuntary loss of urine occurring during sleep [32]. The individual has to wake at night one or more times to void. Nocturia may be a symptom of reduced functional bladder capacity, detrusor overactivity, nocturnal poly-uria or urogenital aging. Nocturia may exacerbate urinary incontinence [28]. Fluids should be limited after supper especially if nocturia is present [33].

\section{Discussion}

The aim was to describe the contributions from nurses in the closely cooperating multidisciplinary team initiatives that address urinary disorders in patients with moderate to severe ABI admitted to hospital-based rehabilitation. Despite the patient's obvious need for complex nursing interventions, and that urination disorders historically are described as a nursing core task descriptions of the nurses' specific efforts were sparse especially among rehabilitation activities to facilitate skills practice $[20,34]$. These efforts might reflect complex interventions with functional and adaptive components to facilitate the patient's recovery [35]. This gap is interesting as a European Competence profile describe teaching, information and support in physical, instrumental and psychological care as a nurse contribution in rehabilitation [36]. The quality of the studies was fluctuating, and the descriptions of how assessment and interventions can be carried out in clinical practice lacks detail. These findings might illustrate the nurse's uncertain professional identity and contributions in neurorehabilitation, which has been described in several studies [11,3741] and the lack of clearly defined contributions may cause challenges for collaboration with the interdisciplinary team, patients and relatives. This might be illustrated in the fact that between 40 and $80 \%$ of patients have urinary disorders but these are seldom addressed in the in the goals of the patients' interdisciplinary rehabilitation plan [24]. The Nurse is required to meet the patient needs in relation to excretion of urination [20], it is the nurse's responsibility to communicate the challenges to the interdisciplinary team in relation to goal setting. Urinary disorders involve nurses but efforts from several professional professionals are needed $[7,24]$. This fact is reflected in clinical guidelines, as these appear to be targeted at the interdisciplinary team $[7,17,19,22,24,27]$. However a urinary disorder is influenced by several parameters such as mobility, movements, dress, communication and cognition kognition [24].

We found abstract descriptions and unclear boundaries between health care professionals and not surprisingly several point to the need for the team's addressing of the problem. This leaves a need for further research in the nurses' contributions in rehabilitation after an ABI.

From a nursing perspective, it is important to identify the evidence for systematic assessment and rehabilitation of urinary disorders [11]. A scoping review was conducted as it is suitable for identifying the scope of available knowledge in a sparingly described field to identify themes prior to a systematic review [21]. Transparency and sound science is achieved through a six-step review process in accordance with recognized descriptions [21]. A reflective circularity was received by a close collaboration between research libraries and all authors during the work process. Finally clinical expert nurses have been consulted on the derived themes and the findings are recognizable in clinical nursing practice. Clinical guidelines appear to be interdisciplinary $[7,17,19,21,22,27]$ and only a modest number of studies conducting a diversity of methods was found to illuminate nurses mono- professional contributions. As a scoping review the quality of each included study was not evaluated. Therefore our finding must be read with great caution.

\section{Conclusion}

Rehabilitation of urinary disorders are complex and require interdisciplinary efforts. Descriptions of nurses' mono-professional contributions are scarce especially among teaching, facilitation 
of skills and psychological care. Supervision from specialist nurses and systematic assessment and examination of the patient's urinary symptoms is a prerequisite for remedial or relieving continencepromoting interventions. Nurses contributions vary between specific types of incontinence and urinary disorders but patients with physical disturbances may need compensatory treatment, aids, physical support and adapted intake while patients with cognitive consequences of ABI may need an organized rehabilitating environment of reminding, visualizing or regular assistance to use the toilet to facilitate continence.

\section{Implications for practice}

Urinary disorders need priority and specialist educated and trained nurses are recommended to guide in neurorehabilitation practice.

Development and implementation of nursing guidelines for systematic assessment and management is recommended.

\section{Urinary disorders need further global attention for nurses.}

Further research is needed to improve the nurses' professional identity and reflexive evidence based practice in the collaboration with the interdisciplinary team.

\section{References}

1. Barker-Collo S, Bennett DA, Krishnamurthi RV, Parmar P, Feigin VL, et al. (2015) Sex differences in stroke incidence, prevalence, mortality and disability-adjusted life years: results from the global burden of disease study 2013. Neuroepidemiology 45 : 203-214. [Crossref]

2. GBD 2016 Traumatic Brain Injury and Spinal Cord Injury Collaborators (2019) Global, regional, and national burden of traumatic brain injury and spinal cord injury, 19902016: a systematic analysis for the Global Burden of Disease Study 2016. Lancet Neurol 18: 56-87. [Crossref]

3. Caldwell S, Wilson J, Smith D, McCann J, Walsh I (2014) Bladder continence management in adult aquired brain injury. Disability and Rehabilitation 36: 959-962.

4. Cournan M (2012) Bladder management in female stroke survivors: translating research into practice. Rehabil Nurs 37: 220-230. [Crossref]

5. Dumoulin C, Korner-Bitensky N, Tannenbaum C, Roth E (2005) Urinary incontinence after stroke: Does rehabilitation make a difference? A systematic review of the effectiveness of behavioral therapy. Topics in stroke rehabilitation 12: 66-76.

6. Oostra K1, Everaert K, Van Laere M (1996) Urinary incontinence in brain injury. Brain Inj 10: 459-464. [Crossref]

7. Tibaek S, Illemann C, Mathiesen L (2015) Nedre urinvejssymptomer hos indlagte apopleksipatienter - udvikling og implementering af en klinisk vejledning. Sygeplejersken 8:81.

8. Matthews M, Mitchell E (2010) Causes and rehabilitation of urinary incontinence after stroke: A litterature review. British journal of neuroscience nursing 6: 37.

9. Clarke DJ (2014) Nursing practice in stroke rehabilitation: systematic review and metaethnography. J Clin Nurs 23: 1201-1226. [Crossref]

10. Thomas L, Coupe J, Cross L, Tan A, Watkins C (2019) Interventions for treating urinary incontinence after stroke in adults. The Cochrane databases of systematic reviews 1 .

11. Chua K, Chuo A, Kong KH (2003) Urinary incontinence after traumatic brain injury: incidence, outcomes and correlates. Brain Inj 17: 469-478. [Crossref]

12. Jamieson K, Brady M, Peacock C (2010) Urinary dysfunction: assessment and management in stroke patients. Nurs Stand 25: 49-55, quiz 56. [Crossref]

13. Pilcher M, MacArthur J (2012) Patient experiences of bladder problems following stroke. Nurs Stand 26: 39-46. [Crossref]

14. Nakayama H, Jørgensen HS, Pedersen PM, Raaschou HO, Olsen TS (1997) Prevalence and risk factors of incontinence after stroke. The Copenhagen Stroke Study. Stroke 28: 58-62. [Crossref]

15. Statens Serum Institut (2015) Forebyggelse af urinvejsinfektion i forbindelse med urinvejsdrænage og inkontinenshjælpemidler. Central Enhed for Infektionshygiejne Number 1: 1 .

16. Shim R, Wong CH2 (2016) Ischemia, Immunosuppression and Infection--Tackling the Predicaments of Post-Stroke Complications. Int J Mol Sci 17. [Crossref]
17. Poisson S, Johnston S, Josephson S (2010) Urinary tract infections complicating stroke: Mechanisms, consequences and possible solutions. Stroke 41: 180.

18. Sundhedsstyrelsen (2011) Hjerneskaderehabilitering - en medicinsk teknologivurdering The National Health Board Issue 1: 13.

19. Sundhedsstyrelsen (2016) National klinisk retningslinje for urininkontines hos kvinder Report. The National Health Board 1

20. Kitson A, Conroy T, Kuluski K, Locock L, Lyons R (2013) Reclaiming and redefining the fundamentals of care: Nursing's response to meeting patients basic human needs. Report number 2. School of Nursing, The University of Adelaide.

21. Peters M, Godfrey C, McLnerney P, Soares C, Khalil H, et al. (2015) The Joanna Briggs institute Reviewers 'manual 2015. Methodology for JBI scoping reviews.

22. Fisher A (2014) Development of clinical practice guidelines for urinary continence care of adult stroke survivors in acute and rehabilitation settings. Canadian Journal of neuroscience nurses 36: 16.

23. Kohler M, Mayer H, Kesselring J, et al. (2018) (Can) Not talk about it - Urinary incontinence from the point of view of stroke survivors: a qualitative study. Scand $J$ Caring Sci 32: 371-379. [Crossref]

24. Leary S, Liu C, Chessman A, Ritter A, Thomson S, et al. (2006) Incontinence afte brain injury: Prevalence, outcome and multidisciplinary management on a neurological rehabilitation unit. Clinical rehabilitation 20: 1094.

25. Wilbert-Herr I, Hürlimann U, Imhof L, Wilbert D (2006) Rehabilitative interventionen zu behandlung der urininkontinenz nach schlaganfall - ein review. Rehabilitacion 45: 289.

26. Herr-Wilbert IS, Imhof L, Hund-Georgiadis M, Wilbert DM (2010) Assessment-guided therapy of urinary incontinence after stroke. Rehabil Nurs 35: 248-253. [Crossref]

27. Slark J, Stewart L (2017) Advances in nursing assessment and management of urinary incontinence for stroke survivors. British Journal of Neuroscience Nursing 13:5:16.

28. Jordan L, Quain M, Marsden D, White J, Bullen K, et al. (2011) Continence Care Following Stroke: What Does It Take?

29. Chandler B (2005) Continence and stroke. In: Recovery after stroke. Barnes M, Dobkin B,Bogousslavsky J, editors. 1st. ed. Cambridge. 415 p.

30. Nazarko L (2003) Rehabilitation and continence promotion following a stroke. Nurs Times 99: 52, 55. [Crossref]

31. Alverzo J, Brigante M, McNish M (2007) Improving stroke outcomes - rehabilitation strategies that work. AJN, American Journal of Nursing 107: 72a-72g.

32. Abrams P, Andersson KE, Birder L, Brubaker L, Cardozo L, et al. (2010) Fourth International Consultation on Incontinence Recommendations of the International Scientific Committee: Evaluation and treatment of urinary incontinence, pelvic organ prolapse, and fecal incontinence. Neurourol Urodyn 29: 213-240. [Crossref]

33. Gross J (2003) Urinary incontinence after stroke: Evaluation and behavioral treatment Topics in geriatric rehabilitation 19: 60 .

34. Henderson V (1997) Basic principles of nursing care. 2nd ed. University of Michigan.

35. Burton C, Gibbon B (2005) Expanding the role of the stroke nurse: a pragmatic clinical trial. $J$ Adv Nurs 52: 640-650. [Crossref]

36. Keeken van P, Woert van der N, Johnston FC (2007) European competence profile of the neuroscience nurse. Report nr 2.

37. Aadal L, Angel S, Dreyer P, Langhorn L, Pedersen BB (2013) Nursing roles and functions in the inpatient neurorehabilitation of stroke patients: A literature review. $J$ Neurosci Nurs 45: 158-170.

38. Kirkevold M (1997) The role of nursing in the rehabilitation of acute stroke patients Toward a unified theoretical perspective. Advances in Nursing Science 19: 55.

39. Kirkevold M (2010) The role of nursing in the rehabilitation of stroke survivors. an extended theoretical account. Advances in Nursing Science 33: E27-E40.

40. Kirkevold M (2014) Introduktion. In: Rehabilterende sygepleje fra begreb til klinisk praksis. Angel S and Aadal L, editors. 1st ed. København: Munksgaard. $17 \mathrm{p}$

41. Loft MI, Martinsen B, Esbensen BA (2017) Strengthening the role and functions of nursing staff in inpatient stroke rehabilitation: developing a complex intervention using the Behaviour Change Wheel. Int J Qual Stud Health Well-being 12: 1392218. [Crossref]

Copyright: (C2019 Fog L. This is an open-access article distributed under the terms of the Creative Commons Attribution License, which permits unrestricted use, distribution, and reproduction in any medium, provided the original author and source are credited. 